\title{
LOST-TIME ILLNESS, INJURY AND DISABILITY AND ITS RELATIONSHIP WITH OBESITY IN THE WORKPLACE: A COMPREHENSIVE LITERATURE REVIEW
}

BEHDIN NOWROUZI ${ }^{1}$, BASEM GOHAR ${ }^{1}$, BEHNAM NOWROUZI-KIA ${ }^{2}$, VICTORIA MINTSOPOULOS 3 , ALICIA MCDOUGALL ${ }^{4}$, GILLIAN JORDAN ${ }^{5}$, JENNIFER CASOLE ${ }^{6}$, MICHEL LARIVIERE ${ }^{1}$, and ANGELO TREMBLAY ${ }^{7}$

${ }^{1}$ Laurentian University, Sudbury, Ontario, Canada

Centre for Research in Occupational Safety and Health

${ }^{2}$ McMaster University, Hamilton, Ontario, Canada

Michael G. DeGroote School of Medicine

${ }^{3}$ Queen's University, Kingston, Ontario, Canada

Faculty of Arts and Science

${ }^{4}$ University of Manitoba, Winnipeg, Ontario, Canada

Rady Faculty of Health Sciences, Department of Occupational Therapy

${ }^{5}$ Ryerson University, Toronto, Ontario, Canada

School of Occupational and Public Health

${ }^{6}$ Loretto College, Toronto, Ontario, Canada

Department of Special Education

${ }^{7}$ Laval University, Quebec City, Quebec, Canada

Department of Social and Preventive Medicine

\begin{abstract}
The objective of this study was to conduct a literature review examining predictors of lost-time injury, illness and disability (IID) in the workplace, with a focus on obesity as a predictor, and to evaluate the relationship between obesity and losttime IID. The study objective was also to analyze workplace disability prevention and interventions aimed at encouraging a healthy lifestyle among employees and reducing obesity and IID, as well as to identify research gaps. The search was conducted in several major online databases. Articles included in the review were published in English in peer-reviewed journals between January 2003 and December 2014, and were found to be of good quality and of relevance to the topic. Each article was critically reviewed for inclusion in this study. Studies that focused on lost-time IID in the workplace were reviewed and summarized. Workers in overweight and obese categories are shown to be at a higher risk of workplace IID, are more likely to suffer from lost-time IID, and experience a slower recovery compared to workers with a healthy body mass index (BMI) score. Lost-time IID is costly to an employer and an employee; therefore, weight reduction may financially benefit both - workers and companies. It was found that some companies have focused on developing interventions that aid reduction of weight and the practice of active lifestyle among their employees. Int J Occup Med Environ Health 2016;29(5):749-766
\end{abstract}

Key words:

Obesity, Disability, Workplace, Injury, Illness, BMI

Received: June 30, 2015. Accepted: November 25, 2015.

Corresponding author: B. Nowrouzi, Laurentian University, Centre for Research in Occupational Safety and Health, 935 Ramsey Lake Road, Sudbury, ON, P3E 2C2, Canada (e-mail: bx_nowrouzi@laurentian.ca). 


\section{INTRODUCTION}

A large global study has emphasized the spread of human obesity, presenting age-standardized obesity rates doubling between 1980 and 2008 [1]. More than $10 \%$ of the world's adult population ( $\geq 20$ years of age) was considered obese in 2008, with more than 1.4 billion adults being in the overweight group, and 500 million of these adults being in the obese group [2]. The growing prevalence of workers who are overweight and obese in numerous countries [3-5] is related to the loss of productivity [6] and lost-time injury. Lost-time Injury, Illness and Disability (IID) can be defined as absence from work due to some form of sickness or workplace injury that is approved by an employer [7]. Such absence can range in severity and duration, resulting in short or long-term disabilities, and encumber social and financial hardship for employees as well as employers.

The increase of obesity in the workplace can lead to potential consequences for an employer and an employee. Between 1980 and 2008, body mass index (BMI) increased $0.4 \mathrm{~kg} / \mathrm{m}^{2}$ in men and $0.5 \mathrm{~kg} / \mathrm{m}^{2}$ in women, every 10 years [8]. There is also evidence that employees have higher rates of presenteeism [9-11] and as a result of increased absenteeism and presenteeism cost the U.S. employers additional 11.7 billion dollars per year compared with normal weight workers [12].

Globalization has had positive effects on the economic development of many nations [13]. However, evidence suggests that globalization creates a labour environment that causes additional stress on employees, leading to changes in work demands (physical to mental tasks) and habits that favor a positive energy balance, which may be responsible for an increase in obesity levels [13]. Modernization and globalization impose lifestyle changes that may affect prevention of work disability and increase the amount of lost-time Illness, Injury and Disability (IID) in the workforce $[13,14]$. Furthermore, globalization of agricultural practices and food industry have had negative implications for population health and obesity epidemic [13]. Globalization and modernization have environmentally contributed to the stress and obesity levels in the workplace and in our society as a whole.

Evidence suggests that obese workers more frequently encounter lost-time IID than workers with normal weight [15]. Consequently, obesity results in negative health and economic outcomes. Employees with a BMI score of $\geq 30$ may be at an increased risk of experiencing workplace IID for numerous reasons including: compromised mobility, fatigue due to sleep apnea or the use of medications that cause sedation to treat diseases, not being able to tolerate hazardous energy exposure, and difficulty engaging in physically demanding job obligations [16]. From an economic standpoint, the cost of obesity among U.S. full-time employees is estimated at 73.1 billion dollars [17]. This is equivalent to the cost of hiring 1.8 million workers per year at 42000 dollars each.

Several reviews have examined the cost and effects of obesity, on disability management, both in the community, as well as in the workplace [17-20]. Although these studies draw links between obesity, sick leave and the non-medical costs of obesity in the workplace, none of these studies have assessed intervention or prevention strategies. The singular exception appears to be that offered by Neovius, who has examined 4 studies of the effect of surgical weight loss interventions on morbidly obese employees [18].

Efforts to reduce the prevalence of obesity in the workplace could result in savings for an employer and health benefits for an employee. It is, therefore, important not only to study the impact obesity has in the workplace, but also possible prevention strategies or interventions, which may mitigate the effects and lessen the burden of illness and injury associated with obesity for both employees and an employer. For employers, this may represent a workforce that is more productive, has lower rates of work absenteeism and decreased operating costs [6]. 


\section{Disability management}

Williams and Westmorland [21] have defined disability management as an employer-based approach to prevent and limit disability, provide an early intervention for risk factors, and promote a safe and early return to work. Disability management includes education and involvement of employees working together as a team, the use of prevention strategies, and many more factors. Crucial factors involved in facilitating return to work include an employer participation, a supportive work environment, and cooperation between laborers and management [21]. Our main interest in this study is the prevention component of disability.

\section{Aims}

The objective of this study was to conduct a literature review examining predictors of lost-time IID in the workplace, focusing on obesity as a predictor, and to evaluate the relationship between obesity and lost-time IID. This study also analyzed strategies and interventions aimed at encouraging a healthy lifestyle among employees and reducing IID, as well as identified gaps in the research on this topic.

\section{MATERIAL AND METHODS}

The information was collected using PubMed, CINAHL, PsycINFO, Social Science Abstracts and Embase/Cochrane databases. The search was completed between June and December 2014. Studies dated from January 2003 to December 2014 were included in this review. Keywords used in the search included: "lost time," "injury" or "injuries," "illness," "disease," "disability," "absence," "prevalence," "workplace," "worker," "occupational," "obesity," "BMI," "workers compensation," "predictors," "prevention," and "intervention." The snowballing technique was also used in the data collection, which involved using the reference lists of articles found through the keywords mentioned above to identify additional related articles.

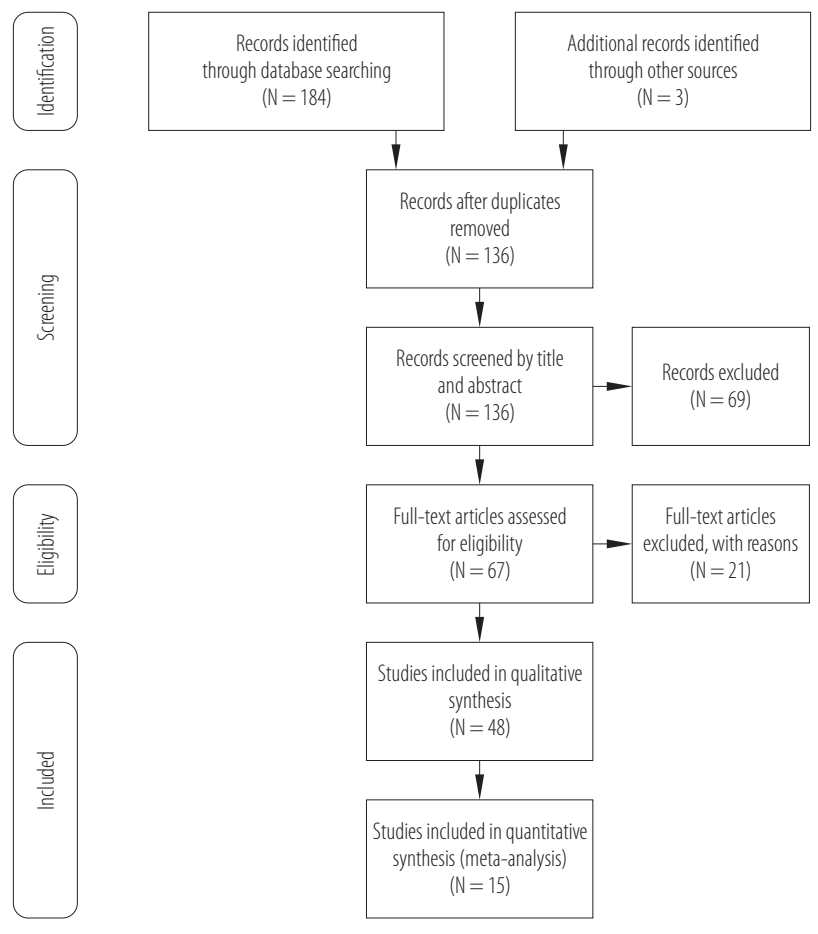

Based on: Moher D, Liberati A, Tetzlaff J, Altman D. The PRISMA Group [54].

Fig. 1. PRISMA flow diagram

We completed an initial title screen, followed by an abstract screen and a full-text review of the selected articles (Figure 1).

Inclusion criteria comprised of the information whether the article explicitly addressed lost-time illness, injury and disability, and its relationship with obesity in the workplace. This review includes both quantitative and qualitative research as well as theoretical articles, including program evaluations. Letters, conference proceeding, abstracts and unpublished manuscripts were excluded. The articles that were included in the review were published in English, in peer-reviewed journals between January 2003 and December 2014, and were found to be of good quality and of relevance to the topic. All members of the research team reviewed decisions regarding the inclusion and exclusion of articles. Articles were excluded if they did not meet the above criteria. Each article was 
critically reviewed for inclusion in this study using the Preferred Reporting Items for Systematic Reviews and MetaAnalyses (PRISMA) flow diagram (Figure 1).

\section{Data analysis}

The Institute of Medicine and the National Research Council Model illustrates the complicated relationship among various factors in the development of disability management through the conceptual model [22]. This model has been acknowledged by both CostaBlack et al. [23] and Schultz et al. [24] in reviews of various conceptual models in the field of disability management. Similarly to Loisel's Work Disability Prevention framework [25], this model was created to portray various factors that may influence development of musculoskeletal disorders in the workplace.

\section{RESULTS}

In order to discuss findings on the lost time IID and BMI more effectively, the results were organized into 2 broad categories: the worker and the workplace. These categories are also used by the Institute of Medicine and National Research Council. Findings from the literature regarding disability prevention and various interventions are also listed below. A summary of findings, arranged by outcome variables, can be found in Tables 1-3.

\section{Obesity and work demands}

Few studies have linked physical work demands and losttime IID, though psycho-social factors in the workplace have been associated with lost-time IID in workers. High work pace, workload and relationship strains with coworkers predicted greater lost-time IID [26-32]. These studies have focused on the workplace and its association with lost-time IID (Table 1). An emphasis has been placed on observing suitability of the workplace environment and work demands for employees in obese BMI categories. The studies suggest making the workplace safer and employees happier through interventions targeted at the entire organization.

\section{Obesity and interventions}

Implementation of obesity prevention or weight management intervention programs and strategies in the workplace, in a form of health promotion or worker wellness programs aimed at weight, nutrition, stress, and physical activity, taking into consideration the obesity rates of today, may be important for employers to consider [33-40] (Table 2 and 3).

In a 2009 meta-analysis by Conn et al. of the health and physical activity behavior outcomes from various workplace wellness intervention studies published between 1969 and 2007, it was found that some interventions were successful at improving employee health. However, effects were variable for most outcomes and further research should be done to compare interventions to confirm any causal relationships [41]. A second meta-analysis by Verweij et al. published in 2010 identified moderate quality evidence supporting workplace physical activity and dietary behavior interventions, especially those containing an environmental component, as significantly reducing body weight, body fat percentage and BMI [42].

In a recent literature review of the effectiveness of workplace health interventions by Schröer et al., beneficial health effects have been found in interventions aimed at workplace nutrition and multi-component physical activity, both of which, when combined, showed a greater effect on weight loss over solely one or the other; however, this review have not found any evidence of increased efficacy associated with any specific intervention reviewed [43]. In another recent literature review published by Fernandez et al. in 2014 of both group-randomized and nonrandomized trials testing environmental interventions for obesity in the workplace, only 4 studies were identified, which met their criteria of performing formative research 


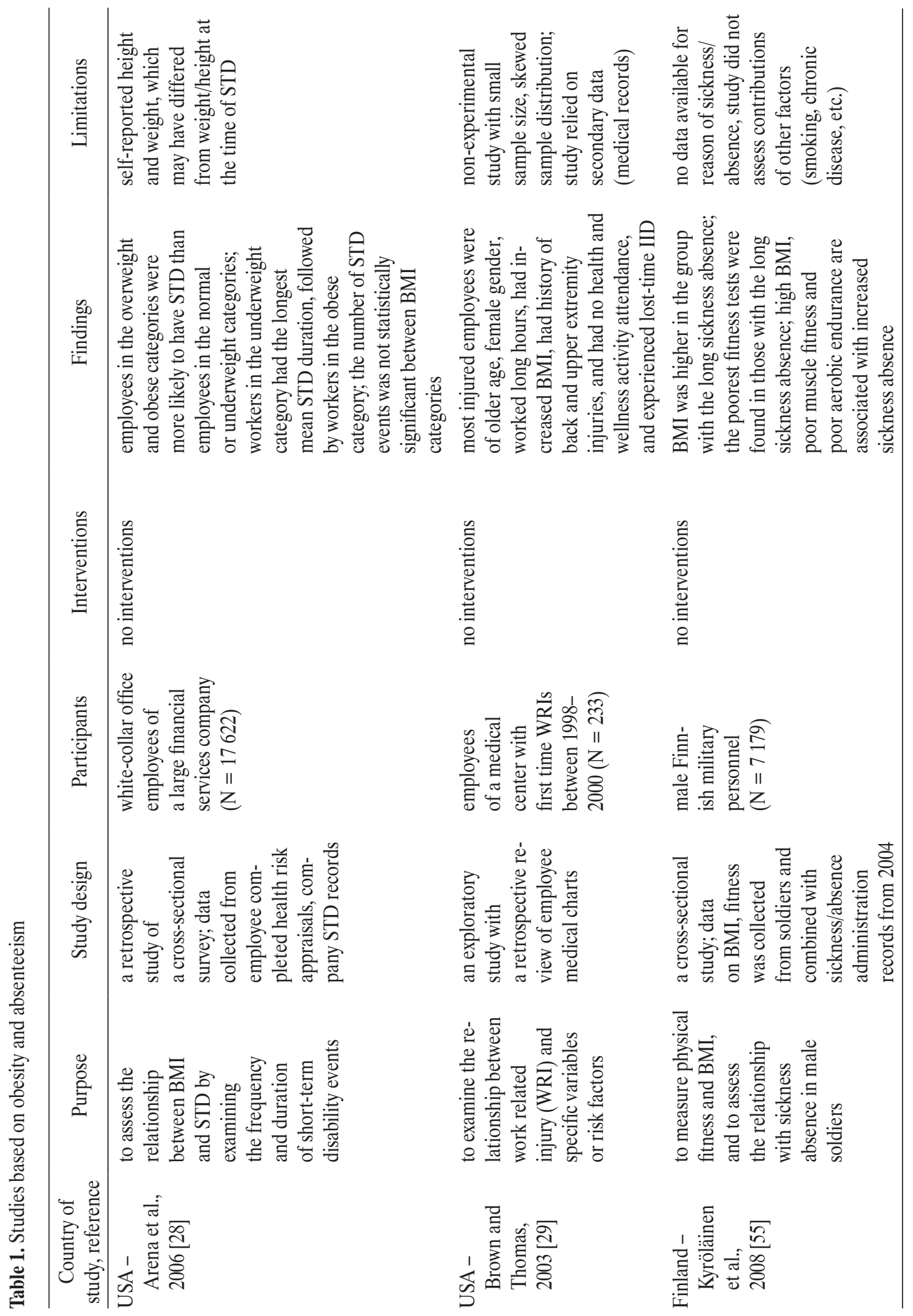




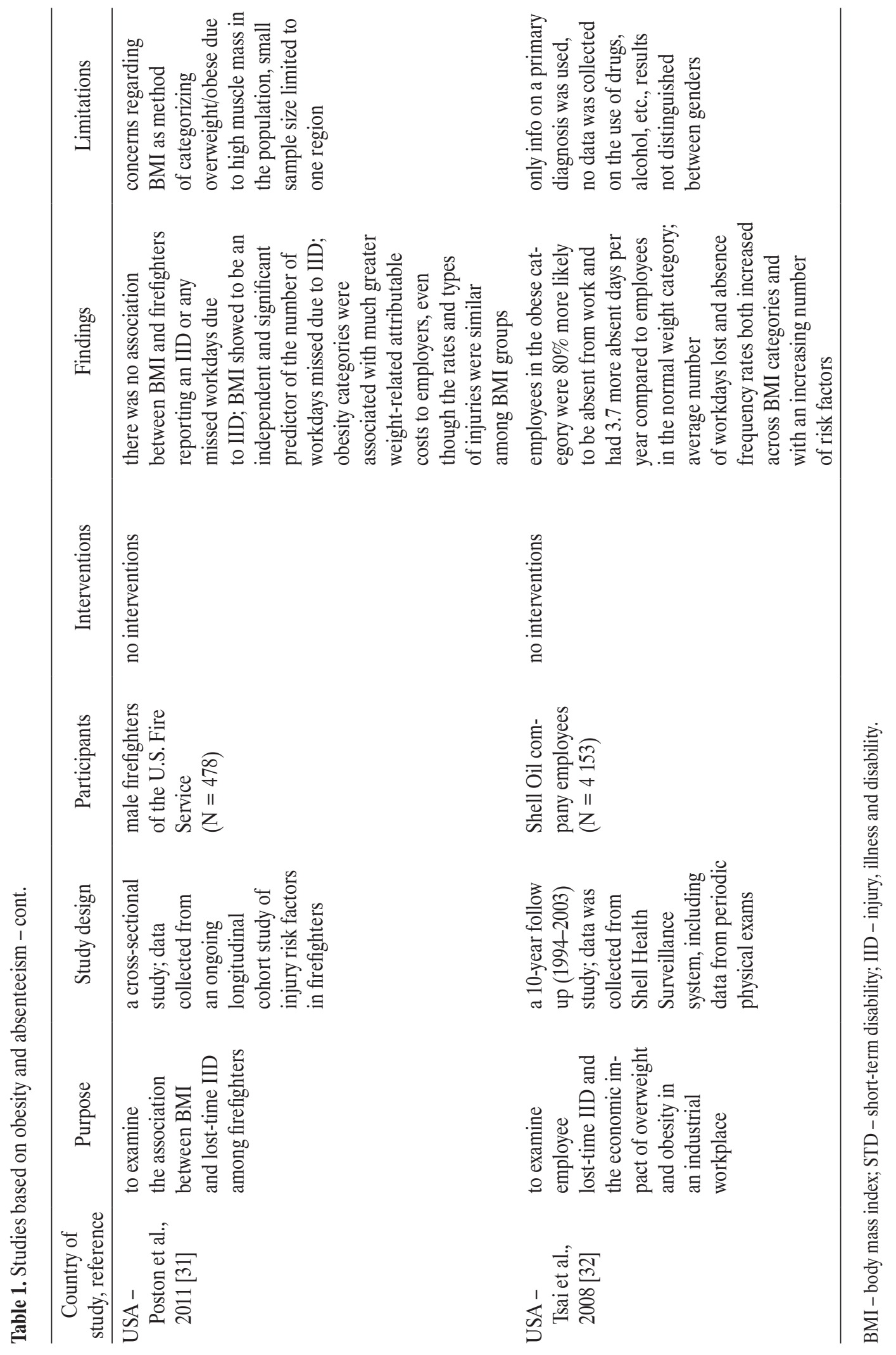




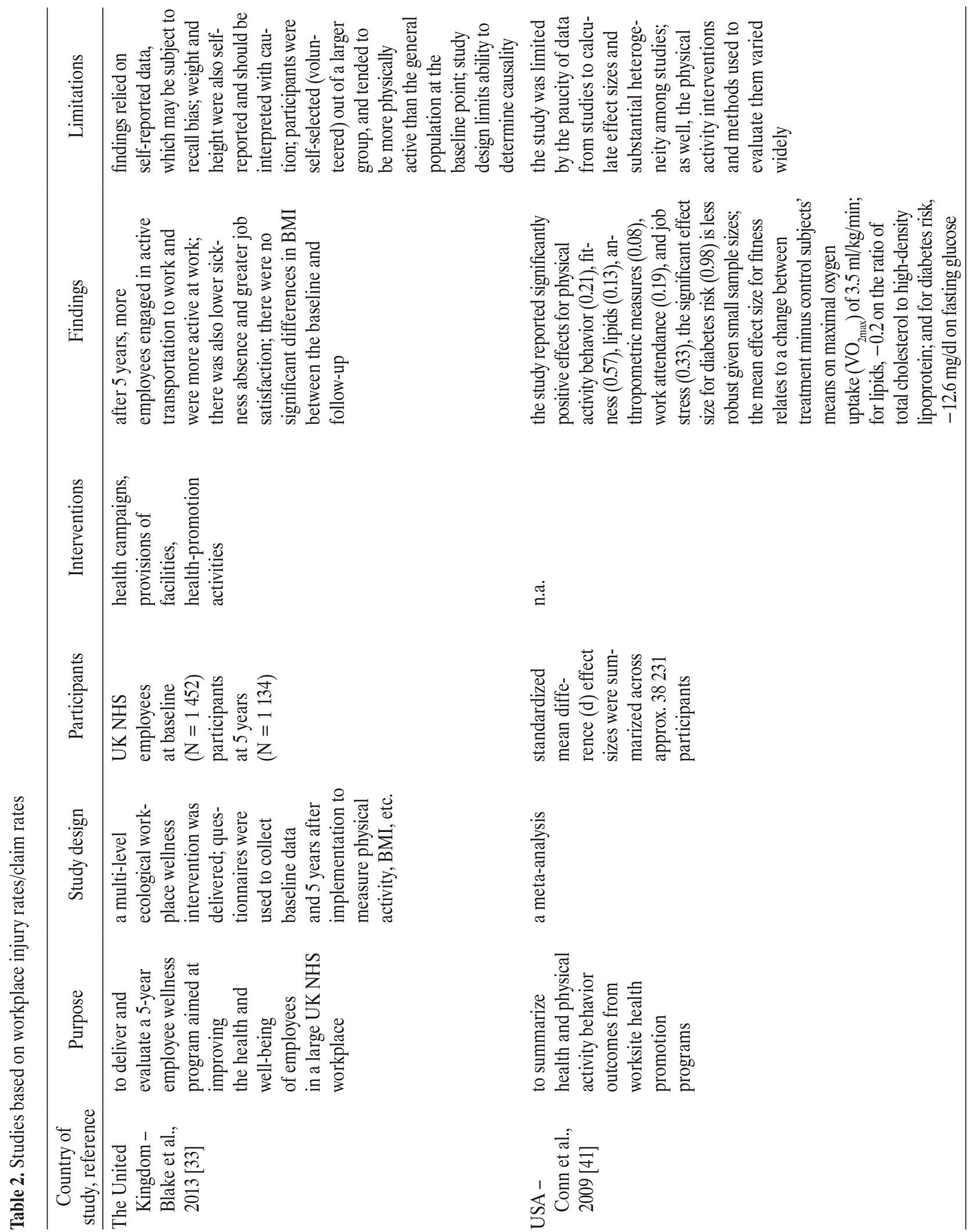




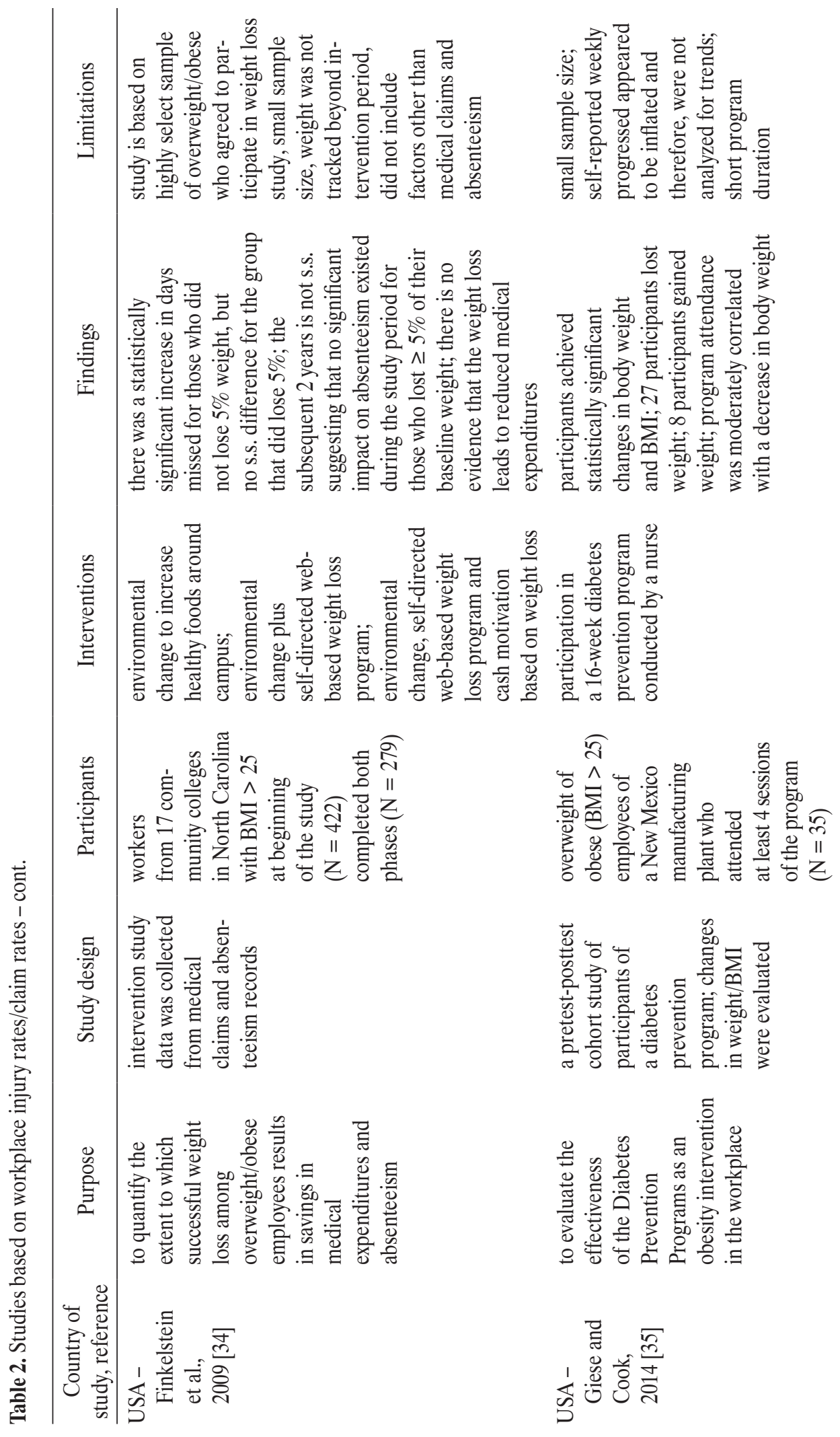




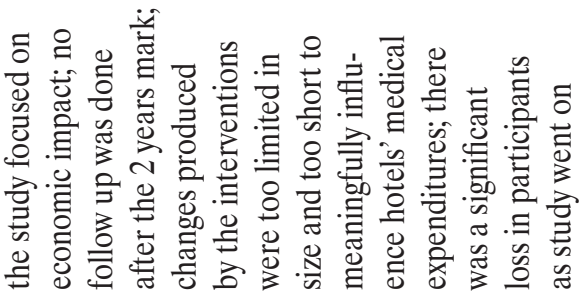

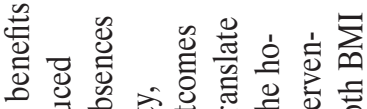

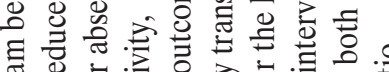

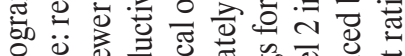

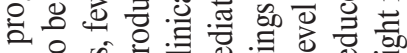

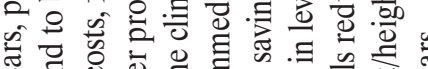

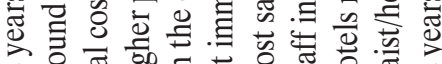

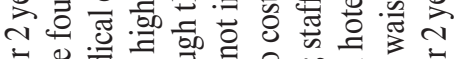

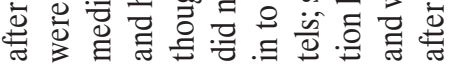

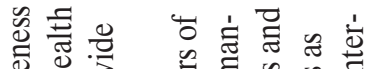

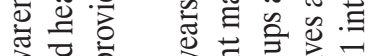

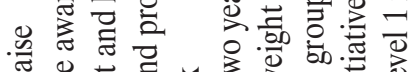

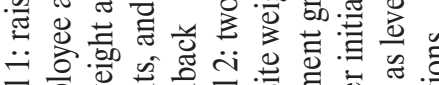

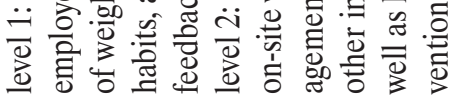

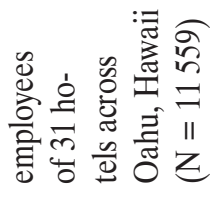

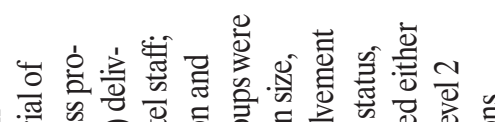

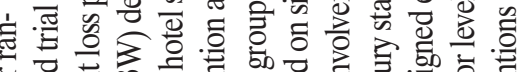

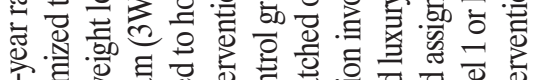

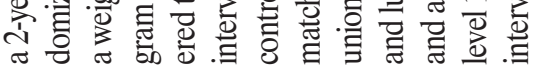

ठํ.

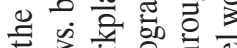

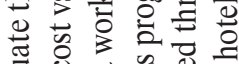

䒕.

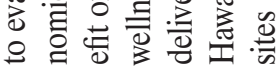

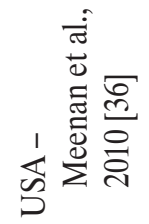

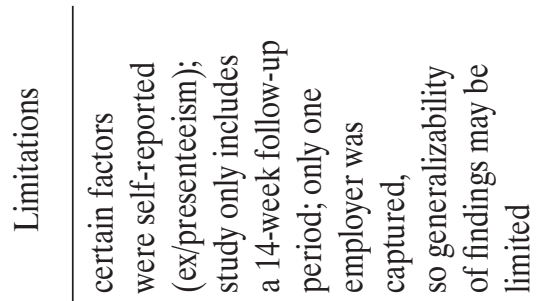

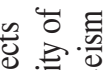

突

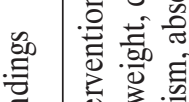

芴

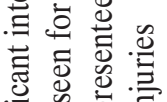

兽高离高

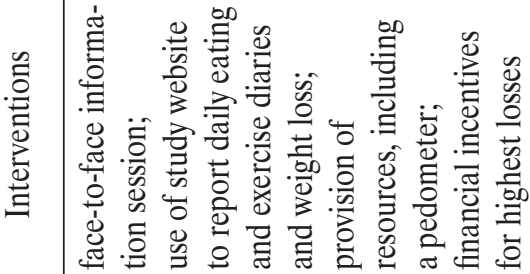

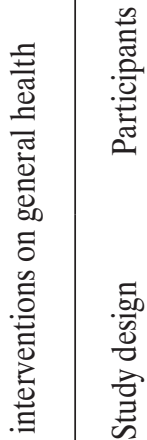

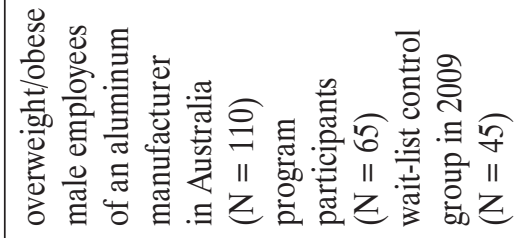

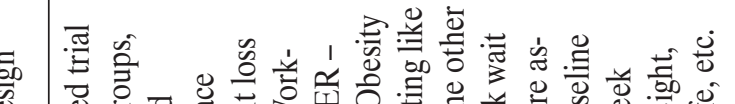

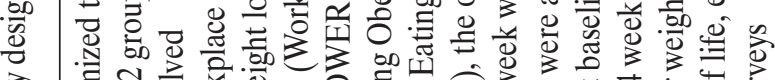

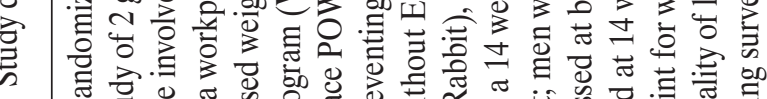

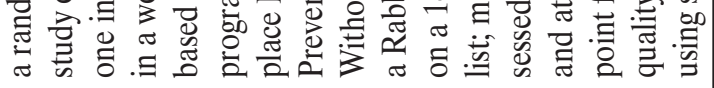

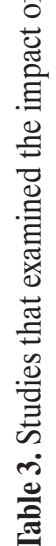




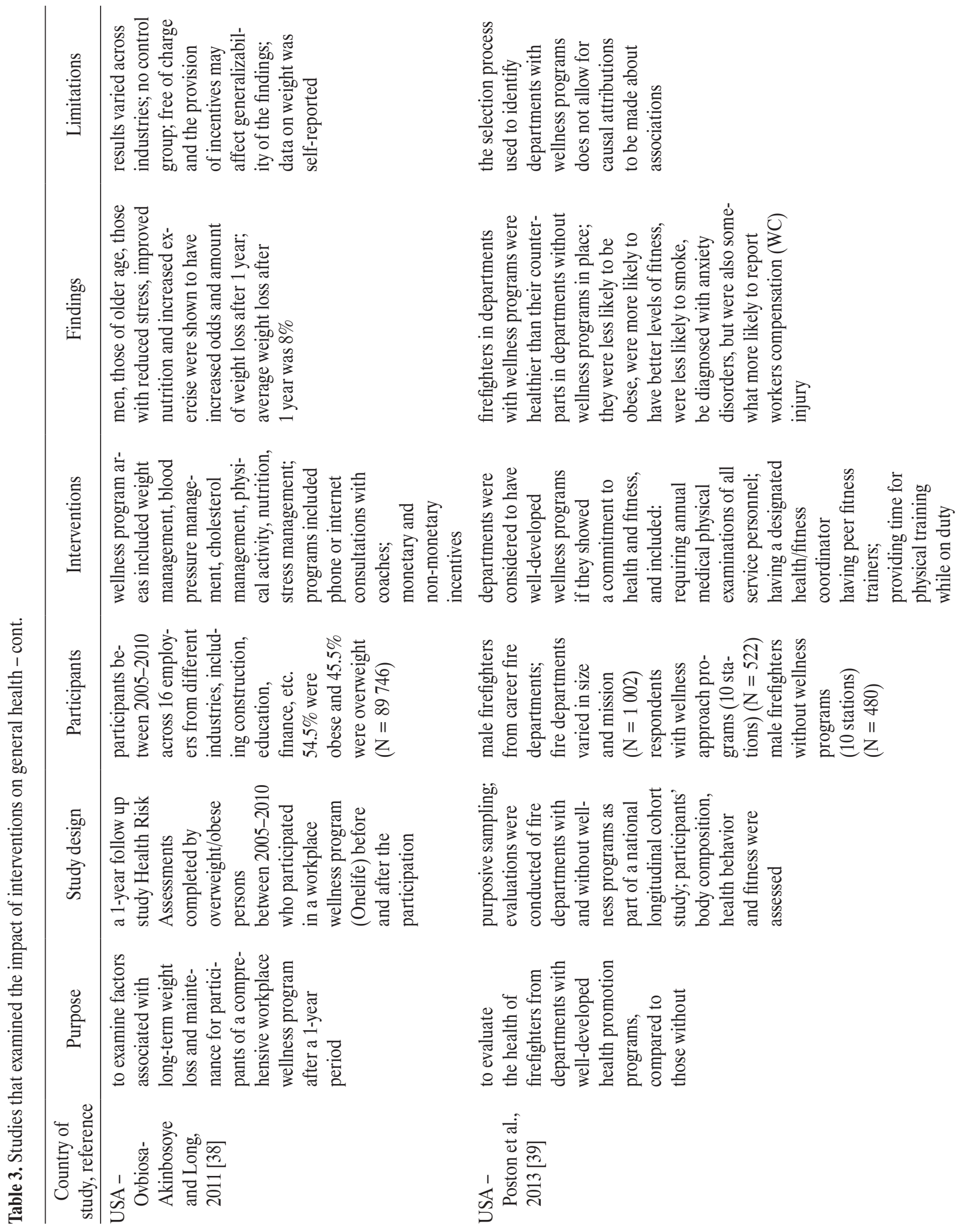



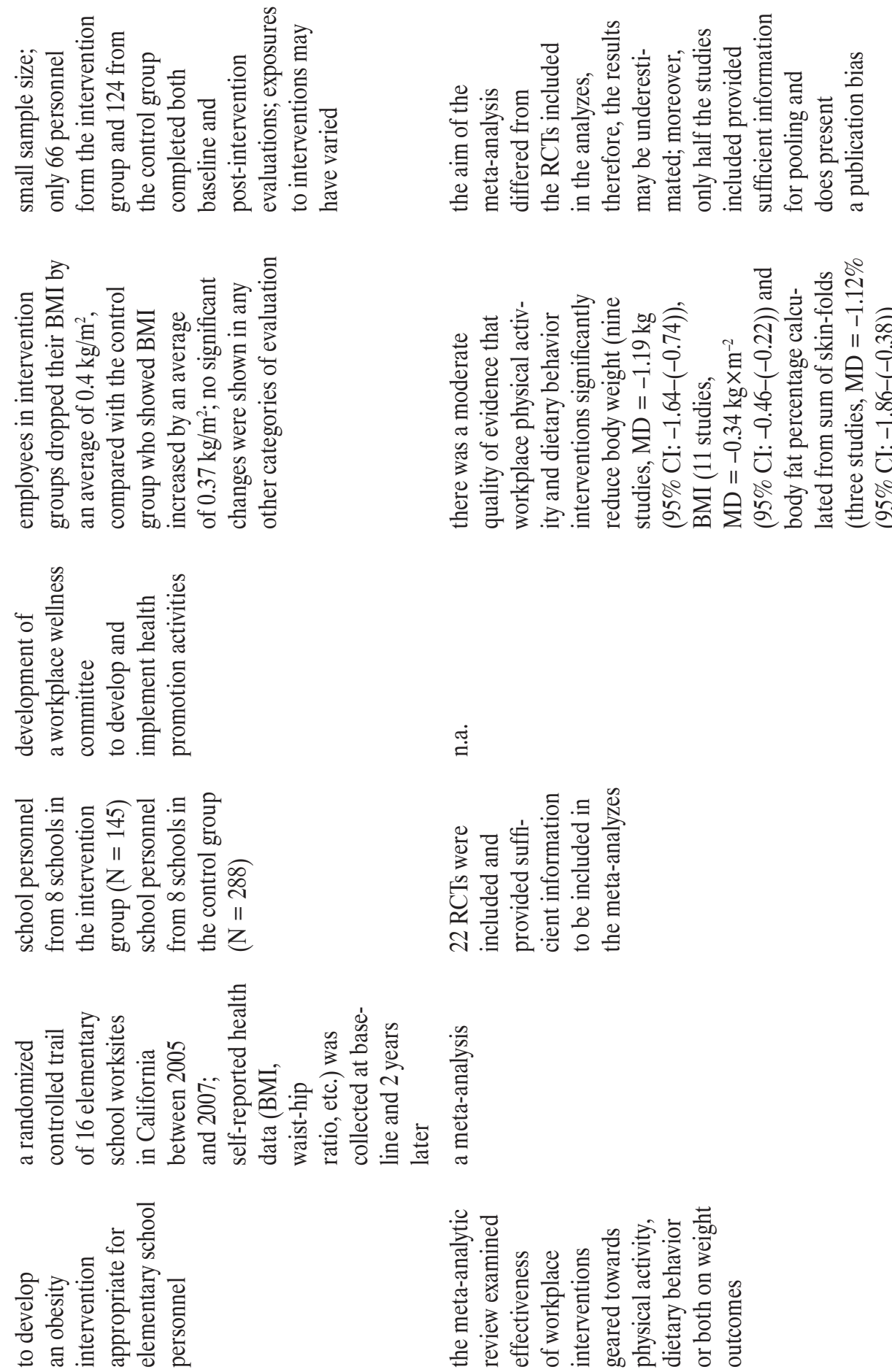

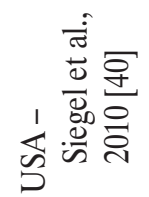

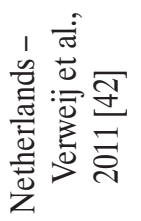


before an development of an intervention or program. None of these studies were able to demonstrate an effect on the main outcome of interest [44]. Fernandez et al., as well as Zinn and Schofield, acknowledge importance of formative data in successful workplace weight interventions, ensuring personalized data is collected and utilized in the development and implementation of the intervention in order to properly match the wants and needs of the target population $[44,45]$.

It is recognized that there is a great variance in the quality of published studies examining various interventions and prevention programs. Certainly, additional quality research is needed to evaluate programs effectiveness, demonstrate the benefits to policy makers and employers, and to ensure a proper balance between the cost and success of such programs [46]. A literature review examining effectiveness of pedometers as a workplace wellness intervention for increasing physical activity and improving health has been found to be limited, to present low quality data and have not provided enough evidence to properly assess effectiveness of the intervention [47]. Another review by Chau et al. of the effectiveness of workplace interventions to reduce sitting and increase active time has shown the lack of evidence on the success of these programs as well [48].

Barriers for success often identified by participants include lack of willpower and cost of healthy food. However, barriers to the implementation of health promotion activities and programs in the workplace can also include misalignment of interests between employers, insurers, service institutes and government [49]. A study by Trogdon et al., which attempted to simulate the return-on-investment of 2 workplace obesity intervention programs, has suggested that opting for lower-cost policy or environmental interventions in worksites may be more likely to result in cost-savings for the employer, rather than high cost interventions, which look to cause behavioral change, as substantial weight loss would need to be experienced in order to see a return [50].
In a 2004 telephone survey conducted by the Research Triangle Institute for Obesity regarding workplace policy strategies for treating and preventing adult obesity, it was found that a vast majority of respondents $(85 \%)$ were in favor of policy change, which would offer their employers tax breaks should they provide exercise facilities in the workplace. Other supported policies included offering employees beneficiary discounts, either by an employer or the healthcare companies, to motivate them to move towards a healthier lifestyle or pursue weight loss [51].

There are obviously many pieces and parties, which come in to play when considering workplace prevention or intervention strategies aimed at health and weight. Though multiple studies exist examining outcomes of specific workplace interventions on obesity, as highlighted in Table 2 and 3, there is an obvious lack of quality, readily available, evidence based data to assist in the development, formation and implementation of such programs. Further research is necessary to ensure appropriate frameworks are available to employers, healthcare providers or other participating bodies in order to enable them to provide effective, meaningful prevention and intervention programs. Also, solid data on the effectiveness, both health and cost related, is important to secure the buy in from employees, employers and policy makers necessary for their success.

\section{DISCUSSION}

The aim of this paper was to review and evaluate the relationship between obesity and lost-time IID in the workplace and to examine prevention and recovery intervention strategies in the workplace. In aggreement with the literature, our review underlined that workers in overweight and obese categories appear to be at a higher risk of workplace IID and are more likely to suffer from lost-time IID. Since lost-time IID is costly to an employer and an employee, weight reduction may financially benefit workers and companies. To do so, lost-time IID prevention 
strategies need to involve consideration and collaboration of various stakeholders, including a worker, workplace, healthcare system, and compensation systems [25].

Concept of weight-loss has received tremendous attention from scientific community over the past few decades and is associated with numerous physical, physiological and psychological health improvements. However, since obesity is a multifactorial and complex condition, employers and their employees need to collaborate in order to optimize their chances of success.

To start with, employees need to be educated about the possible health consequences associated with being overweight and its financial impact on the workplace IID. To do so, employers should consider offering educational workshops and conferences promoting healthy lifestyle behaviors to help employees make informed decisions. Moreover, in order to encourage employees to seek the expertise needed, employers need to facilitate access to healthcare professionals by providing sufficient annual health coverage and/or offering on-site work consultations.

Professionals will then be able to help employees target specific causes that might lead to weight gain and increased lost-time IID, and to put appropriate solutions in place. Along those lines, an employer can promote active lifestyle behaviors by providing access to on-site physical activity installations or if this is not possible, to compensate employees subscribing to organized exercise classes or physical activity centers. Moreover, in order to favor healthy eating, employers need to make sure they offer an affordable and healthy alternative menu at the cafeteria.

It is now better known that successful long-term weight management includes strategies that consider a broad range of behaviors including sedentary ones, nutritional and physical activity habits, stress management, etc. Along those lines, our review suggests that clinicians investigating a patient's medical, social and psychological history could benefit from adding occupational history to this list. Indeed, an average worker spends approximately $8 \mathrm{~h}$ per day in his/her workplace. Thus, clinicians should be encouraged to investigate a patient's work environment including factors related to the workplace and the person.

Researchers have worked with companies to develop interventions that are aimed at workplace IID prevention, though further research must be directed at studying IID recovery interventions. These recovery strategies should be specified by occupation because every job involves its own specific demands. For example, a construction worker must lift heavy objects, while a white-collared employee may spend majority of his or her working hours at a desk. Considering the amount of time and money obesity in the workplace has cost, companies have targeted their focus on developing interventions that are tailored to different occupational settings $[33,35,37,39,40]$.

In turn, employees often know what makes a workplace vibrant. Their recommendations for improvement push far beyond health promotion programs into issues such as economic rewards, hours, and schedules, relationships with co-workers and more input, and job resources. Moreover, among those employees whose work interfered with their personal life, reduced workload was also a soughtafter change, followed closely by more flexible work accommodations [52].

Employers who are motivated by the imperatives of productivity, competiveness, flexibility and efficiency need to be made aware of the growing evidence that work quality (e.g., skill, discretion, autonomy, consultation and a healthy work environment) all contribute directly to the achievement of their goals [53]. Employers must work together with their employees to achieve their goals. Overcoming organizational barriers to change is challenging, and many employers are trapped in old ways of thinking about people issues in the workplace. For instance, heavy workload and time scarcity are major change barriers in nursing. 
These obstacles invariability are identified as holding managers back from doing more to promote a healthy organization [52]. Furthermore, overworked employees won't espouse a new change initiative, even one aimed at improving their work environment [52]. The best way for managers to become facilitators of healthy change is to directly involve them in improving the drivers of health and increasing quality of work life in the work setting for their employees.

Finally, governments could also promote partnerships with employers, works and unions, educational and training institutions, and other labour-market stakeholders. In Europe, employers, workers, unions and governments tend to see one another as partners. Within many organizations, workers are consulted on issues affecting and pertaining to them. Works Councils, in which such discussions take place, are becoming more and more common across Europe.

Critics argue that this more worker friendly approach comes at the expense of less flexibility, overstaffing and generous social security benefits that have crippled European industries and states. However, these opponents neglect the way organization of work in Europe is changing: bureaucratic restrictions are being eased and new technologies introduced, there is greater work flexibility in work assignment, job responsibilities are expanding, training and education opportunities are improving. The mindset is that work should encompass more than paid employment and consider social, political and economic aspects as well. This approach is vital in shaping public policy and guiding occupational health strategies in improving the quality of work life of workers.

\section{Limitations}

This review contains a number of limitations. First, only articles written in English were included in our search. Second, BMI values determining which weight category employees are placed into were not consistent throughout the articles reviewed. Several researchers grouped underweight and ideal weight employees together, while others separated them, and a few of the articles classified larger BMI scores into 3 obese subcategories. Furthermore, BMI scoring is not an overall plausible classification for obesity, as muscle is not taken into consideration.

Body fat percentage may be a superior form of measurement; however, this technique is costly and can be unreliable. Studies were not consistent with the process of obtaining weight and height data from the studies populations, as some were self-reported and others were acquired through physical examinations. This may have an effect on the accuracy of the overall results. Study populations varied greatly in size, where smaller groups could have an adverse effect on the results, as the study may be overrepresented. A distinct set of BMI ranges and categories must be put to use in all future studies in order to make reliable comparisons. Lastly, researchers should formulate outcome measurements related to the success of work disability prevention interventions in order to distinguish which strategies are most productive and effective. Researchers should consider performing more thorough follow-ups on these interventions for significant results to be found after long durations.

\section{CONCLUSIONS}

Workers with a high BMI are more likely to suffer from lost-time IID and experience a slower recovery compared to workers with a healthy BMI score. Obesity in the workplace increases absenteeism and presenteeism, which financially impacts employees and their employer. In order to benefit both the health of employees and the productivity of a company, thorough IID prevention strategies and weight reduction interventions should be implemented. As extensive research has been put into analyzing losttime IID in the workplace, some studies have evaluated more cofounding variables and risk factors in comparison to others. Gaps exist in research focused on IID and 
disability prevention because many of these studies fail to be thorough in the explanations of their prevention strategies. Experts in the field of workplace IID and workplace disability should establish specific guidelines stating steps and strategies to prevent IID in workplace environments. Further studies revolving around IID prevention and intervention should be conducted on various job types and settings, where researchers are clear on how they aim to prevent the most common and severe injuries found in specific work fields, or how they have implemented intervention strategies where existing issues have been identified.

There also should be clear measurements of progress for returns to the workplace. Additional studies focused on employees returning to work should be conducted and analyzed for specific job types and work injuries. This will result in developing the most efficient and cost-beneficial approaches to return workers back to their workplace.

Increase in obesity levels over the last decade, and the increase that is hypothesized for the future, is dangerous to employees' health and contributes to the workplace lost-time IID. Employers with a high obesity rate in their workplace should be encouraged to offer their workers weight reduction programs, which is another area where additional research would be greatly beneficial.

Employers should take the initiative to review daily practices of their workers. This will allow employers to become aware of the physical and cognitive demands they are requesting from their employees. Employers may then acknowledge alterations that should be made in order to reduce stress levels among their employees. This, in turn, could result in a decrease in obesity levels in the workplace. Future research regarding IID prevention, intervention, return to work and weight reduction programs should be practiced for a significant amount of time and followed-up years later. Longitudinal and follow-up studies could help determine if the interventions or strategies were significantly beneficial.

\section{REFERENCES}

1. Finucane MM, Stevens GA, Cowan MJ, Danaei G, Lin JK, Paciorek CJ, et al. National, regional, and global trends in body-mass index since 1980: Systematic analysis of health examination surveys and epidemiological studies with 960 country-years and 9.1 million participants. Lancet. 2011;377(9765):557-67, http://dx.doi.org/10.1016/S01406736(10)62037-5.

2. World Health Organization [Internet]. Geneva: The Organization; 2016 [updated Jan 2015; cited 2015 May 25]. Obesity and overweight. Available from: http://www.who.int/mediacentre/factsheets/fs311/en/.

3. Stevens GA, Singh GM, Lu Y, Danaei G, Lin JK, Finucane MM, et al. National, regional, and global trends in adult overweight and obesity prevalences. Popul Health Metr. 2012;10(1):22, http://dx.doi.org/10.1186/1478-7954-10-22.

4. Rennie K, Jebb S. Prevalence of obesity in Great Britain. Obes Rev. 2005;6(1):11-2, http://dx.doi.org/10.1111/j.1467789X.2005.00164.x.

5. Ng M, Fleming T, Robinson M, Thomson B, Graetz N, Margono $\mathrm{C}$, et al. Global, regional, and national prevalence of overweight and obesity in children and adults during 19802013: A systematic analysis for the Global Burden of Disease Study 2013. Lancet. 2014;384(9945):766-81, http://dx.doi. org/10.1016/S0140-6736(14)60460-8.

6. Finkelstein EA, DiBonaventura MdC, Burgess SM, Hale BC. The costs of obesity in the workplace. J Occup Environ Med. 2010;52(10):971-6, http://dx.doi.org/10.1097/ JOM.0b013e3181f274d2.

7. Whitaker S. The management of sickness absence. Occup Environ Med. 2001;58(6):420-4, http://dx.doi.org/10.1136/ oem.58.6.420.

8. Borak J. Obesity and the workplace. Occup Med. 2011;61(4):220-2, http://dx.doi.org/10.1093/occmed/kqr030.

9. Gates DM, Succop P, Brehm BJ, Gillespie GL, Sommers BD. Obesity and presenteeism: The impact of body mass index on workplace productivity. J Occup Environ Med. 2008;50(1): 39-45, http://dx.doi.org/10.1097/JOM.0b013e31815d8db2. 
10. Loeppke R, Taitel M, Haufle V, Parry T, Kessler RC, Jinnett K. Health and productivity as a business strategy: A multiemployer study. J Occup Environ Med. 2009;51(4):411-28, http://dx.doi.org/10.1097/JOM.0b013e3181a39180.

11. Liss-Levinson RC, Goetzel RZ, Goodman N, Kennedy JX. Development of a community-wide cardiovascular risk reduction assessment tool for small rural employers in upstate New York. Prev Chronic Dis. 2009;6(2):A65.

12. Ricci JA, Chee E. Lost productive time associated with excess weight in the US workforce. J Occup Environ Med. 2005;47(12):1227-34, http://dx.doi.org/10.1097/01. jom.0000184871.20901.c3.

13. Huneault L, Mathieu MÈ, Tremblay A. Globalization and modernization: An obesogenic combination. Obes Rev. 2011;12(5):e64-72, http://dx.doi.org/10.1111/j.1467789X.2010.00817.x.

14. Jordan G, Nowrouzi-Kia B, Gohar B, Nowrouzi B. Obesity as a possible risk factor for lost-time injury in registered nurses: A literature review. Saf Health Work. 2015;6(1):1-8, http://dx.doi.org/10.1016/j.shaw.2014.12.006.

15. Lin T, Verma SK, Courtney TK. Does obesity contribute to non-fatal occupational injury? Evidence from the National Longitudinal Survey of Youth. Scand J Work Environ Health. 2013;39(3):268-75, http://dx.doi.org/10.5271/sjweh.3347.

16. Pollack KM, Cheskin LJ. Obesity and workplace traumatic injury: Does the science support the link? Inj Prev. 2007;13(5):297-302, http://dx.doi.org/10.1136/ip.2006. 014787.

17. Van Duijvenbode DC, Hoozemans MJM, van Poppel MNM, Proper KI. The relationship between overweight and obesity, and sick leave: A systematic review. Int J Obes. 2009;33(8):807-16, http://dx.doi.org/10.1038/ijo.2009.121.

18. Neovius K. Obesity status and sick leave: A systematic review. Obes Rev. 2009;10(1):17-27, http://dx.doi.org/10.1111/ j.1467-789X.2008.00521.x.

19. Trogdon JG. Indirect costs of obesity: A review of the current literature. Obes Rev. 2008;9(5):489-500, http://dx.doi. org/10.1111/j.1467-789X.2008.00472.x.
20. Norton L, Harrison JE, Pointer S, Lathlean T. Obesity and injury in Australia: A review of the literature. Canberra: Australian Institute of Health and Welfare; 2011.

21. Williams RM, Westmorland M. Perspectives on workplace disability management: A review of the literature. Work. 2002;19(1):87-93.

22. Panel on Musculoskeletal Disorders and the Workplace, Commission on Behavioral and Social Sciences and Education, National Research Council, Institute of Medicine. Musculoskeletal disorders and the workplace: Low back and upper extremities. Washington DC: National Academy Press; 2001.

23. Costa-Black KM, Cheng AS, Li M, Loisel P. The practical application of theory and research for preventing work disability: A new paradigm for occupational rehabilitation services in China? J Occup Rehabil. 2011;21:15-27, http:// dx.doi.org/10.1007/s10926-011-9296-2.

24. Schultz IZ, Stowell AW, Feuerstein M, Gatchel RJ. Models of return to work for musculoskeletal disorders. J Occup Rehabil. 2007;17(2):327-52, http://dx.doi.org/10.1007/s10926007-9071-6.

25. Loisel P, Durand M-J, Berthelette D, Vezina N, Baril R, Gagnon D, et al. Disability prevention. New paradigm for the management of occupational back pain. Dis Manage Health Outcomes. 2001;9(7):351-60, http://dx.doi. org/10.2165/00115677-200109070-00001.

26. Kouvonen A, Kivimäki M, Oksanen T, Pentti J, de Vogli R, Virtanen M, et al. Obesity and occupational injury: A prospective cohort study of 69,515 public sector employees. PLoS One. 2013;8(10):e77178, http://dx.doi.org/10.1371/ journal.pone.0077178.

27. Welch LS. Impact of musculoskeletal and medical conditions on disability retirement - A longitudinal study among construction roofers. Am J Ind Med. 2010;53(6):552-60, http://dx.doi.org/10.1002/ajim.20794.

28. Arena VC, Padiyar KR, Burton WN, Schwerha JJ. The impact of body mass index on short-term disability in the workplace. J Occup Environ Med. 2006;48(11):1118-24, http:// dx.doi.org/10.1097/01.jom.0000241050.26059.2b. 
29. Brown ND, Thomas NI. Exploring variables among medical center employees with injuries: Developing interventions and strategies. AAOHN J. 2003;51(11):470-81.

30. Labriola M, Lund T, Burr H. Prospective study of physical and psychosocial risk factors for sickness absence. Occup Med. 2006;56(7):469-74, http://dx.doi.org/10.1093/occmed/ $\mathrm{kq1058.}$

31. Poston WSC, Jitnarin N, Haddock CK, Jahnke SA, Tuley BC. Obesity and injury-related absenteeism in a population-based firefighter cohort. Obesity. 2011;19(10):2076-81, http://dx.doi.org/10.1038/oby.2011.147.

32. Tsai SP, Ahmed FS, Wendt JK, Bhojani F, Donnelly RP. The impact of obesity on illness absence and productivity in an industrial population of petrochemical workers. Ann Epidemiol. 2008;18(1):8-14, http://dx.doi.org/10.1016/j.annepidem.2007.07.091.

33. Blake H, Zhou D, Batt ME. Five-year workplace wellness intervention in the NHS. Perspect Public Health. 2013;133 (5):262-71, http://dx.doi.org/10.1177/1757913913489611.

34. Finkelstein EA, Linnan LA, Tate DF, Leese PJ. A longitudinal study on the relationship between weight loss, medical expenditures, and absenteeism among overweight employees in the WAY to Health study. J Occup Environ Med. 2009;51(12):1367-73, http://dx.doi.org/10.1097/ JOM.0b013e3181c2bb56.

35. Giese KK, Cook PF. Reducing obesity among employees of a manufacturing plant: Translating the Diabetes Prevention Program to the workplace. Workplace Health Saf. 2014;62(4):136-41, http://dx.doi.org/10.3928/2165079920140305-02.

36. Meenan RT, Vogt TM, Williams AE, Stevens VJ, Albright CL, Nigg C. Economic evaluation of a worksite obesity prevention and intervention trial among hotel workers in Hawaii. J Occup Environ Med. 2010;52 Suppl 1:S8-13, http://dx.doi.org/10.1097/JOM.0b013e3181c81af9.

37. Morgan PJ, Collins CE, Plotnikoff RC, Cook AT, Berthon B, Mitchell S, et al. The impact of a workplace-based weight loss program on work-related outcomes in overweight male shift workers. J Occup Environ Med. 2012;54(2):122-7, http://dx.doi.org/10.1097/JOM.0b013e31824329ab.

38. Ovbiosa-Akinbosoye OE, Long DA. Factors associated with long-term weight loss and weight maintenance: Analysis of a comprehensive workplace wellness program. J Occup Environ Med. 2011;53(11):1236-42, http://dx.doi.org/10.1097/ JOM.0b013e31823401db.

39. Poston WSC, Haddock CK, Jahnke SA, Jitnarin N, Day RS. An examination of the benefits of health promotion programs for the national fire service. BMC Public Health. 2013;13:805, http://dx.doi.org/10.1186/1471-2458-13-805.

40. Siegel JM, Prelip ML, Erausquin JT, Kim SA. A worksite obesity intervention: Results from a group-randomized trial. Am J Public Health. 2010;100(2):327-33, http://dx.doi. org/10.2105/AJPH.2008.154153.

41. Conn VS, Hafdahl AR, Cooper PS, Brown LM, Lusk SL. Meta-analysis of workplace physical activity interventions. Am J Prev Med. 2009;37(4):330-9, http://dx.doi. org/10.1016/j.amepre.2009.06.008.

42. Verweij L, Coffeng J, van Mechelen W, Proper K. Metaanalyses of workplace physical activity and dietary behaviour interventions on weight outcomes. Obes Rev. 2011;12(6): 406-29, http://dx.doi.org/10.1111/j.1467-789X.2010.00765.x.

43. Schröer S, Haupt J, Pieper C. Evidence-based lifestyle interventions in the workplace - An overview. Occup Med. 2014;64(1):8-12, http://dx.doi.org/10.1093/occmed/kqt136.

44. Fernandez ID, Becerra A, Chin NP. Worksite environmental interventions for obesity prevention and control: Evidence from group randomized trials. Curr Obes Rep. 2014;3(2): 223-34, http://dx.doi.org/10.1007/s13679-014-0100-4.

45. Zinn C, Schofield G. Using formative work to enhance a workplace weight loss maintenance intervention: Balancing what employees want and what they need. Nutr Diet. 2012;69(4):265-71， http://dx.doi.org/10.1111/j.17470080.2012.01607.x.

46. Thorndike A. Workplace interventions to reduce obesity and cardiometabolic risk. Curr Cardiovasc Risk Rep. 2011;5(1):79-85, http://dx.doi.org/10.1007/s12170-010-0138-0. 
47. Freak-Poli RLA, Cumpston M, Peeters A, Clemes SA. Workplace pedometer interventions for increasing physical activity. Cochrane Database Syst Rev. 2013;4:CD009209, http://dx.doi.org/10.1002/14651858.CD009209.pub2.

48. Chau JY. Are workplace interventions to reduce sitting effective? A systematic review. Prev Med. 2010;51(5):352-6, http://dx.doi.org/10.1016/j.ypmed.2010.08.012.

49. Cherniack M, Lahiri S. Barriers to implementation of workplace health interventions: An economic perspective. J Occup Environ Med. 2010;52(9):934-42, http://dx.doi. org/10.1097/JOM.0b013e3181f26e59.

50. Trogdon J, Finkelstein EA, Reyes M, Dietz WH. A returnon-investment simulation model of workplace obesity interventions. J Occup Environ Med. 2009;51(7):751-8, http:// dx.doi.org/10.1097/JOM.0b013e3181a86656.

51. Fuemmeler BF, Baffi C, Mâsse LC, Atienza AA, Evans WD. Employer and healthcare policy interventions aimed at adult obesity. Am J Prev Med. 2007;32(1):44-51, http://dx.doi. org/10.1016/j.amepre.2006.09.003.

52. Lowe G. Creating healthy organizations: How vibrant workplaces inspire employees to achieve sustainable success. Toronto: University of Toronto Press; 2010.

53. Lowe G. The quality of work: A people-centered agenda. Toronto: Oxford University Press; 2000.

54. Moher D, Liberati A, Tetzlaff J, Altman D. The PRISMA Group. Preferred reporting items for systematic reviews and meta-analyses: The PRISMA statement. PLoS Med. 2009;6(7):1-6.

55. Kyröläinen H, Häkkinen K, Kautiainen H, Santtila M, Pihlainen K, Häkkinen A. Physical fitness, BMI and sickness absence in male military personnel. Occup Med. 2008;58(4):251-6, http://dx.doi.org/10.1093/occmed/kqn010.

This work is available in Open Access model and licensed under a Creative Commons Attribution-NonCommercial 3.0 Poland License - http://creativecommons.org/ licenses/by-nc/3.0/pl/deed.en. 